\title{
JUSTIÇA TRANSICIONAL E DESENVOLVIMENTO SUSTENTÁVEL: DESAFIOS DE UMA PAZ DURADOURA EM UM MUNDO EM TRANSFORMAÇÃO.
}

\author{
Transitional justice and sustainable development: challenges \\ of a lasting peace in a changing world.
}

\section{Kiwonghi Bizawu}

\begin{abstract}
Advogado, sacerdote, mestre e doutor em Direito Internacional pela Pontifícia Universidade Católica de Minas Gerais, professor de Direito Internacional Público e Privado no curso de graduação e de Fundamentos de Metodologia da Pesquisa Cientifica no Mestrado em Direito Ambiental e Desenvolvimento Sustentável na Escola Superior Dom Hélder Câmara - Belo Horizonte - MG.

E-mail: sebak_07@hotmail.com
\end{abstract}

RECEBIDO EM: 07.09.12

APROVADO EM: 25.11.12

\section{RESUMo}

O presente artigo analisa a complexidade do fenômeno da globalização do mundo jurídico pela eficácia e legitimidade do Tribunal Penal Internacional (TPI), destacando, contudo, a politização de uma justiça seletiva, assimétrica e discriminatória, menos universal, tendo em vista as contradições geradas pelos crimes cometidos pelos dirigentes das grandes potências, financiadores de conflitos armados no mundo afora. Destaca-se, desse modo, partindo de uma pesquisa explicativa assentada no método hipotético dedutivo, a necessidade da Justiça Transicional como contra ponto ao TPI em busca de uma paz duradoura e de um desenvolvimento sustentável baseada no resgate da memória das vítimas e da consciência coletiva na perspectiva de reescrever a história dos povos lesados e buscar a verdade mediante as Comissões Verdade e Reconciliação.

Palavras-Chave: Globalização. Corte Penal Internacional. Desenvolvimento sustentável. Justiça Transicional. 


\begin{abstract}
This paper analyzes the complexity of the phenomenon of globalization of the legal world for the effectiveness and legitimacy of the International Criminal Court (ICC), emphasizing, however, the politicization of a selective justice, unbalanced and discriminatory, less universal, given the contradictions generated by crimes committed by the leaders of the great power, funders of armed conflicts in the world. It is noteworthy, therefore, from an explanatory research based on hypothetical deductive method, the need for Transitional Justice as counter point to the ICC in search of as lasting peace and sustainable development based on retrieval of the memory of the victims and the collective consciousness in perspective rewrite the history of people injured and seek the truth by the Truth and Reconciliation Commissions.
\end{abstract}

Keyswords: Globalization. International Criminal Court. Sustainable Development. Transitional Justice.

SUMÁRIo: Introdução. 1. Importância da justiça internacional e novos paradigmas. 2. Tribunal Penal Internacional e justiça transicional. 3. Comissões verdade e (re)conciliação ou justiça pós-conflitos. 3.1. Entendimento da justiça transicional no âmbito internacional. 3.2. Natureza jurídica da Comissão Verdade e Reconciliação (CVR). 3.3. Nova forma de comunicação e instauração de um diálogo sustentável. 4. A Comissão Verdade e Reconciliação: desafios. 4.1. Comissão Verdade e Reconciliação: uma luta contra a impunidade. 4.2. Comissão Verdade e Reconciliação para construção de um Estado de direito. Conclusão. Referências.

\title{
INTRODUÇÃo
}

O trabalho em pauta, além de destacar a importância da globalização jurídica realçada pela criação do Tribunal Penal Internacional (TPI) "com caráter permanente e independente, no âmbito do sistema das Nações unidas, e com jurisdição sobre os crimes de maior gravidade que afetem a comunidade internacional no seu conjunto" ${ }^{265}$, procura ressaltar também a necessidade da Justiça Transicional em um mundo em transformação para a promoção da

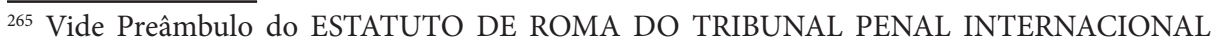
(1998). 
paz social duradoura e do desenvolvimento sustentável fundada na busca da Verdade e Reconciliação e do resgate da memória das vítimas.

Apesar das inovações observadas nos tempos atuais e a desenfreada mobilidade de pessoas, sabe-se que, mesmo aparecendo em estado embrionário, o processo da globalização é velho como o mundo, contrariamente ao que pensam algumas pessoas, pois, desde os tempos remotos, as civilizações antigas mantiveram contatos entre si, apesar da violência que emanava das relações entre os povos de diferentes culturas, religiões, traduzida pela escravidão ou pelas guerras que dizimavam populações inteiras.

Quanto à mobilidade, Rüdiger Dahlke (2011) entende que:

[...] a moderna palavra mágica mobilidade é na verdade antiquíssima e já se manifesta no "Pantha rhei" ("tudo flui") de Heráclito. Ocorre que só nos falta encontrar o plano certo. Um ser humano com uma extraordinária mobilidade espiritual tem alegria de viver e é um ganho para o meio ambiente. Somente se cair no extremo das ideias fugazes é que ele se tornará um problema. Mesmo no plano social a mobilidade é uma vantagem. (DAHLKE, 2011, p. 116).

Comparando aqueles tempos da antiguidade e das sociedades como as mais conhecidas (grega, judaica, chinesa e romana, incas, maias e astecas), sem olvidar as que nasceram na Idade Média e Idade Moderna, pode-se observar que o processo da globalização tem trazido profundas mudanças e indubitáveis transformações em todos os setores, especialmente no de informática com nova tecnologia e várias inovações. Trata-se, nesse caso, de um desafio permanente a qual fica adstrita a sociedade vigente. Tal mudança acarreta, ipso facto, uma transformação significativa das instituições e uma quebra de paradigmas.

Nota-se, dessa forma, que o Direito, não sendo uma ciência estática, determinista, também está em constantes mutações, procurando uma adequação mais equilibrada e uma adaptação normativa mais eficaz e justa com as transformações da própria sociedade, visando, além disso, uma maior integração entre diferentes comunidades, uma verdadeira cooperação entre Estados, favorecendo, portanto, relações amistosas ou harmoniosas entre povos de diferentes culturas, línguas e raças ou etnias.

De forma panorâmica, pode-se destacar a importância da informática dentro do processo da globalização, ao encurtar as distâncias entre seres humanos, quebrando as barreiras que até então separavam os povos, favorecendo, para tanto, relações amistosas ou, em outros casos, a xenofobia e a discriminação racial. 
O estrangeiro deixou de ser o outro absoluto que vive do outro lado do oceano ou atrás de fronteiras intransponíveis e se tornou um vizinho, o que explica o recrudescimento do racismo nesses países, sob a forma do crescimento dos movimentos fascistas e neonazistas. Ao ter que conviver com esse estrangeiro, transformado em vizinho, percebe-se quão difícil é reconhecê-lo como próximo, e amá-lo como a si mesmo. O que antes fosse, talvez, possível devido à distância, torna-se quase que impossível devido à proximidade, que faz com que se acabe por imputar a esse outro um gozo excessivo, acusando-o de querer estragar nosso modo de vida (KOLTAR, 1997, p.73).

A globalização da economia que, de um lado, tem provocado intensas ondas migratórias para novos eldorados, e do outro, tem revelado a briga entre as grandes potências em busca de novas fontes de recursos naturais para o crescimento industrial e da liderança no campo econômico a fim de controlar o mercado dos minerais raros, mas importantes para a revolução industrial em sintonia com a revolução "verde", tornou-se um dos fatores de conflitos entre grandes potências através das multinacionais instaladas nos Estados em desenvolvimento.

No mundo jurídico, constata-se também a influência do fenômeno da globalização, o que, na realidade, não é novidade, mas uma consequência de abertura entre vários sistemas judiciários, em nome da cooperação judiciária internacional para acompanhar a pessoa física ou jurídica em suas constantes mutações ou processo migratório.

No âmbito do direito internacional, fica patente a influência da globalização, porém, não deixa de suscitar discussões no que se refere ao princípio da justiça universal que rompe, em certos graus, com os princípios da soberania e da autodeterminação dos povos.

$\mathrm{O}$ cerne desse artigo encontra-se no advento do Tribunal Penal Internacional que trouxe, no ato de sua criação, uma luz de esperança para a humanidade sedenta de justiça diante dos crimes gravíssimos com alcance internacional, mas, no decorrer do tempo, considerando os atuais processos, o mesmo Tribunal tem se tornado seletivo, assimétrico e discriminatório por julgar apenas supostos criminosos do leste europeu e senhores de guerra e ditadores africanos, poupando os dirigentes ocidentais, especificamente, das grandes potências tais como Estados Unidos da América (EUA), Reino Unido e França pelos crimes cometidos no Iraque, Afeganistão e Guantánamo. É comum ocorrer discriminação e assimetria, na comunidade internacional, quando se trata de efetivação de sanções contra as grandes potências no tocante a violações de direitos humanos e de descumprimento de metas relativas a convenções 
internacionais sobre o Meio Ambiente e desenvolvimento Sustentável.

Por conta desse cenário cruel e maquiavélico (mas realista) que esse artigo procura fazer um contra ponto à Justiça Internacional, ressaltando a necessidade e a relevância da Justiça Transicional em um mundo em transformação como meio eficaz em determinados Estados onde etnias, tribos, populações ou povos com culturas diferentes vivem em contínua discórdia ou em conflitos armados, podendo, tais desavenças, desencadear crimes de genocídio, crimes de guerra e crimes contra a humanidade, sendo crimes da competência do Tribunal Penal Internacional pela inteligência dos artigos $5^{\circ}-8^{\circ}$ do Estatuto de Roma.

Com a detida análise, o artigo abordará, em um primeiro momento, a importância da Justiça Internacional para pôr fim à impunidade dos autores dos crimes de maior gravidade que constituem uma ameaça à paz, à segurança e ao bem-estar da humanidade, assim como faz jus o preâmbulo do próprio Estatuto de Roma e a necessidade de adotar novos paradigmas diante da crise que conhece a justiça internacional acusada de ser parcial, seletiva, assimétrica e discriminatória pelos Estados em desenvolvimento.

Em seguida, analisar-se-á a relação entre o Tribunal Penal Internacional e a Justiça Transicional, buscando pontos que possam ajudar em uma eventual reformulação da Justiça Internacional, tendo em vista as acusações sobre a parcialidade do Procurador no tocante à seleção das pessoas responsáveis pelos crimes de maior gravidade com alcance internacional, colocando em xeque a efetivação da justiça internacional.

Tal entendimento ajudará na abordagem da Justiça Transicional e Comissões da Verdade, trazendo à baila as dificuldades encontradas na composição de tais comissões e sua efetivação em alguns Estados da América Latina e, dando-se, ao final uma sucinta análise sobre a Constituição da República Federativa do Brasil e o Tribunal Penal Internacional, bem como a importância da criação da Comissão Verdade recentemente instalada para resgatar a memória das vitimas na ditadura militar no Brasil.

\section{IMPORTÂNCIA DA JUSTIÇA INTERNACIONAL E NOVOS PARADIGMAS}

Tem-se observado, ultimamente, um esforço internacional para fortalecer a cooperação judiciária entre Estados e Organizações internacionais em nome da segurança internacional. Desde os atentados de 11 de setembro de 2001 contra as Torres Gêmeas, em Nova Iorque, a tendência é de reforçar-se a cooperação judiciária entre Estados e, ao mesmo tempo, dar um sinal claro e forte aos criminosos, no tocante a terrorismo e crimes gravíssimos com alcance internacional, tais como crimes de genocídio, crimes de guerra e crimes contra a humanidade. Crimes esses que a comunidade internacional procura combater, 
principalmente a sensação da impunidade e da letargia das quais é acusada diante das violações sistemáticas dos direitos humanos. É de coibir qualquer ato contra a dignidade humana.

A prisão em Londres (16 de outubro de 1998), mediante mandado de prisão internacional emitido pelo juiz espanhol Baltazar Garzón ${ }^{1}$, do ditador chileno, até então senador vitalício, o General Augusto Pinochet, provocou uma grande revolução do direito internacional. O juiz solicitara a extradição do mesmo para a Espanha, a fim de responder às acusações relativas a torturas, sequestro, detenções ilegais, deslocamentos forçosos, desaparecimentos e eliminação seletiva de cerca de três mil pessoas no Chile.

De qualquer forma, estamos em uma Era de direitos, como dizia Norberto Bobbio $^{266}$, considerando a velocidade com que acontecem eventos no mundo inteiro, exigindo uma resposta clara, imediata e objetiva diante dos assuntos jurídicos na contemporaneidade. Existe uma crescente demanda para com o direito internacional e uma necessidade de cooperação internacional entre Estados e respectivos sistemas judiciários. É o caso, por exemplo, da pirataria ${ }^{2}$ tanto nas águas internacionais como no mar territorial da Somália. A comunidade internacional tem se preocupado com a proliferação de sequestros de navios nas águas territoriais somalis e no canal de Aden, onde nota-se uma mobilização internacional para garantir a segurança dos navios e dos marinheiros.

A globalização jurídica, nesse caso, é um verdadeiro desafio diante da inexistência de normas uniformes para julgar, no caso concreto, os piratas capturados pelas forças navais de vários Estados enviados nas águas da Somália.

Cabe, nesse caso, indagar diante das novas e desafiadoras perspectivas da Justiça Internacional: o que fazer com os piratas capturados? Qual seria a jurisdição competente para julgá-los? Em caso de conflitos de leis no espaço, qual o direito aplicável para dirimir a lide?

Questiona-se, ainda, a impunidade de que gozam os militares americanos tanto no Iraque como no Afeganistão diante das violações sistemáticas de direitos humanos naqueles países e a perseguição à qual são submetidos dirigentes de Estados em desenvolvimento, especialmente, africanos, considerados responsáveis pelos crimes de maior gravidade com alcance internacional.

Merece destaque, também, o assassinado de Bin Laden pelas tropas americanas em violação flagrante da integridade territorial do Paquistão onde se escondia o "terrorista" mais procurado da humanidade depois do julgamento dos militares e civis nazistas em Nuremberg (1946).

\footnotetext{
${ }^{266}$ Vale lembrar que se trata do mesmo Juiz espanhol Baltazar Garzón que defende atualmente Julian Assange, o fundador de Wikileaks, jornalista e ciberativista autraliano, refugiado na embaixada da República do Equador em Londres, o qual lhe concedeu o asilo político, evitando, para tanto a extradição para a Suécia onde responde por crimes sexuais.
} 
Importante frisar que, já no auto do mandado de prisão internacional decretado pela Justiça espanhola, por intermédio do juiz Garzón (1998) contra Pinochet, abriu-se um precedente jurídico na história do direito internacional por se tratar da detenção de um ex-chefe de Estado que, até aquele momento, gozava de imunidade senatorial vitalícia, concedida pelo povo chileno.

Surgem, ainda, outras indagações sobre a legitimidade da Justiça Internacional para poder estender sua competência até as pessoas que gozam de privilégios e imunidades no exercício de suas funções, e não em benefício próprio como prêmio para permanecer na impunidade. O que fazer para que a Justiça Internacional não seja acusada de parcialidade por favorecer as grandes potências, ou seja, ser uma justiça a serviço dos vencedores em detrimento dos fracos? Os Estados Unidos da América fazem pressão sobre o Sudão para entregar o presidente Omar El Bechir ao TPI, com base no Estatuto de Roma que eles mesmos não ratificaram, passando-se, lamentavelmente, por campeões de democracia e de direitos humanos devido à organização das primeiras eleições democráticas no Iraque pós Saddam Hussein e no Afeganistão, liberado, parcialmente, do domínio dos talibãs.

Com efeito, o mandado de prisão contra o presidente sudanês, Omar El Bechir, em 04 de março de 2009, veio reavivar a polêmica em torno da questão de que a África não seria o único continente onde são cometidos crimes de guerra ou crimes contra a humanidade, razão pela qual houve protestos de vários dirigentes africanos que se sentiram visados pela medida. Do outro lado, há de se questionar tal pedido do procurador do TPI porque é impensável que o mesmo mandado seja lançado contra o ex-presidente americano George W. Bush pelos crimes de guerra e crimes contra a humanidade cometidos no Iraque. Quem ousaria prender o presidente e o primeiroministro israelenses pelos mesmos crimes nos territórios palestinos?

Segundo Noam Chomsky (1999, p. 66), os Estados Unidos da América (EUA) jamais são condenados pelas resoluções do Conselho de Segurança, pois as vetam.

$\mathrm{Na}$ mesma esteira, ele explica que a lei internacional também não é aplicável aos Estados Unidos, pois fazem o que bem entendem. (p.66)

Você pode encontrar inúmeras resoluções que condenam os EUA e jamais foram aprovadas - resoluções que teriam recebido aprovação, se tratassem de um país indefeso. E a Assembleia Geral aprova resoluções o tempo todo, mas elas não têm força - são apenas recomendações. (CHOMSKY, 1999, p. 67)

O Relatório da Organização das Nações Unidas (ONU) sobre os crimes de guerra e crimes contra a humanidade praticados pelos militares israelenses 
denominados Relatório Goldstone nivelou o grau de responsabilidade dos militares do Tshalaa e dos militantes de Hamas pelos crimes cometidos durante a guerra na faixa de gaza, imputando, neste caso, a ambas as partes a violação da Convenção de Genebra de 1949. Tais fatos provocam indignação e fazem acreditar que a Justiça internacional seria mais severa para com os acusados dos Estados em desenvolvimento do que para com os dirigentes das grandes potências que, aliás, querem ver os primeiros encarcerados, humilhados e julgados para servir de aviso aos outros criminosos.

Comentando a decisão do TPI sobre o mandado de detenção contra o presidente Omar Al Bechir do Sudão, o presidente venezuelano Hugo Chávez lembrou que os dirigentes ocidentais faziam aquilo por se tratar de um país africano e de terceiro mundo. Para ele, o Presidente americano G.W. Bush merecia um mandado de detenção internacional. "Por que não ordenaram a captura do Bush? Por que não ordenaram a captura do Presidente de Israel? Segundo Chávez a ordem de prisão contra Omar Al Bechir é um despropósito jurídico e um desrespeito aos povos do terceiro mundo ${ }^{267}$.

Na mesma ocasião, Jean Ping, Presidente da Comissão da União Africana, criticando uma justiça seletiva, disse em tom lapidário que o TPI havia sido criado para julgar os africanos. Sem embargo, a maioria dos casos abertos no TPI concerne ao continente africano devido à intensidade de conflitos com relação aos outros continentes, porém não se pode deduzir que os crimes de guerra ou crimes contra a humanidade apenas ocorrem na África ${ }^{2683}$.

Observa-se, de fato, uma desconfiança quanto ao funcionamento do TPI com relação aos dirigentes dos Estados em desenvolvimento, os únicos visados no momento, apesar da intensidade de crimes da competência do TPI cometidos tanto na faixa de Gaza como no Iraque ou Afeganistão, bem como na China contra os Uigures ou contra o Tibet. Falila Gbadamasi, em seu artigo intitulado "CPI: une justice pour Áfrique", aborda no mesmo sentido ao indagar se "em

\footnotetext{
${ }^{267}$ Trata-se de uma obra que recolhe os artigos que Bobbio considera principais, escritos ao longo de muitos anos sobre o tema dos direitos do homem, assim como ele mesmo o testemunha na introdução do mesmo livro. "[...] São onze ensaios, nascidos em ocasiões diversas (comunicações em simpósios, conferências em universidades italianas e estrangeiras, opúsculos autônomos), mas que têm em comum a emergência, constante e orgânica, de algumas teses: os direitos naturais são direitos históricos; nascem no início da era moderna, juntamente com a concepção individualista da sociedade; tornam-se um dos principais indicadores do progresso histórico." (Comentário na contracapa de BOBBIO, Norberto. A Era dos direitos. Trad. Carlos Nelson Coutinho. Rio de Janeiro: Campus, 1992).

${ }^{268}$ A questão da pirataria será abordada adiante quanto aos desafios da jurisdição internacional diante do surgimento de novas tendências. Qual seria o Tribunal competente para julgar os piratas capturados nas águas internacionais, querendo sequestrar um cargueiro? A que Justiça serão submetidos esses piratas? Disponível em: http://cpcmbm.blogspot.com.br/2009_03_01_archive. html. Acessado em: 30.07. 2012.
} 
nome da justiça internacional, o TPI teria o poder de perturbar George Bush, expresidente da primeira potência econômica e militar a respeito de Guantánamo, qualificado por Anistia Internacional de "símbolo de um governo que não respeita suas obrigações jurídicas internacionais"269 (tradução nossa).

Há de registrar, ainda, que a criação dos dois Tribunais Penais Internacionais ad hoc, um para ex-Iugoslávia e outro para Ruanda provocara ásperas discussões e críticas duras por seu caráter parcial e seletivo. Nesse sentido observam Jean-Paul Bazelaire e Thierry Cretin (2004, p.63):

[...] Mas os dois TPIs, considerados por alguns dos partidários da justiça penal internacional como o laboratório experimental da CPI, foram criticados por outros partidários dessa mesma justiça como sendo a instituição de uma justiça parcial, visto que ad hoc: uma justiça seletiva no tempo e no espaço, enquanto a justiça é, por definição, universal e permanente. A instituição da CPI responde a essa crítica tentando atenuá-la $[\ldots]$.

Pode-se dizer, dentre os crimes da competência do TPI que ela não julga pessoas detidas arbitrariamente como alega Patrice Despretz, diretor da Revista Actualité et Droit International, citado por Falila Gbadamassi, porém não se pode olvidar que a prisão de Guantánamo é um exemplo típico, gritante e vergonhoso de violação de princípios de direito internacional, inclusive tratado nas convenções de Genebra no que concerne aos prisioneiros de guerra. Dáse a ideia de que as detenções arbitrárias são legais e legítimas como seria a própria guerra no Iraque e no Afeganistão mesmo não tendo a chancela da ONU. Procura-se legalizar o que é ilegítimo e legitimar o que é ilegal e contra os princípios consuetudinários das relações internacionais. O fato de os Estados Unidos e o Sudão não serem signatários do Estatuto de Roma lhes dá o direito de cometer os crimes da competência da CPI e gozarem da impunidade.

Ora, para que um caso referente aos crimes enumerados no art. $5^{\circ}$ - do Estatuto de Roma seja submetido ao TPI e esta possa exercer a sua jurisdição, precisa-se de três hipóteses, a saber: a denúncia deve ser feita por um Estado Parte ao Procurador, nos termos do art. 14, ou pelo Conselho de Segurança (CS), agindo nos termos do Capítulo VII da Carta das Nações Unidas, fazendo denúncia ao Procurador de tais crimes, ou ainda o próprio Procurador poderá iniciar um inquérito sobre os crimes nos termos do art. 15.

\footnotetext{
269 "Au nom de la justice internationale, la CPI aurait-elle le pouvoir d"inquiéter George Bush, ancien président de la première puissance économique et militaire à propos notamment de Guantânamo, qualifié par Amnesty International de "symbole d"un gouvernement ne respectant pas ses obligations juridiques internationales? ”
} 
O surpreendente é que os Estados Unidos são membro permanente do Conselho de Segurança e, mesmo não sendo signatários do Estatuto, sentemse privilegiados para se pronunciar apenas na instituição onde têm peso e direito de veto. Por que, em casos semelhantes, não se aplica a política de dois pesos duas medidas pelos crimes praticados por G. W. Bush no Iraque com base na mentira sobre armas de destruição em massa que detinha Saddam Hussein? Crimes inimagináveis foram cometidos pelos militares americanos no Iraque contra os muçulmanos e pelos militares israelenses nos territórios palestinos, sendo, portanto, considerados crimes de guerra ou crimes contra a humanidade, passíveis de julgamento perante o TPI, porém nada foi dito nem feito. Simplesmente, ignoraram-se a justiça internacional e o princípio da autodeterminação dos povos, vilipendiando-se a memória das vítimas.

Por se tratar de Estados com maior influência no mundo, seus crimes são minimizados, existindo uma série de razões para justificar as guerras sujas e tornando-as justas, legais e legítimas em nome da paz e da segurança internacionais. Tudo o que é ilegal é legitimado quando, na concepção americana e de seus aliados, aquilo representa uma ameaça para o mundo. Na realidade, cabe aos grandes ditarem os parâmetros da justiça mundial à luz do Cap. VII da Carta de São Francisco, de 1945, a qual, na realidade no século XXI, merece uma revisão, uma releitura ou uma reinvenção considerando os problemas vigentes, de modo especial, para que garanta o cumprimento da Declaração dos Direitos Humanos (1948).

Daí a necessidade de dar chance à diplomacia, pois, em certos casos, a justiça internacional reflete os aspectos políticos de quem detém o poder no mundo, ou seja, percebe-se a mão poderosa, mas escondida, das grandes potências, principais contribuintes da ONU e que se dão ao luxo de mandar e desmandar na condição da política internacional em todos os setores, econômico, político e judicial.

Tem-se em evidência a continuidade do jogo de poder no TPI, pois, é sabido que, em hipótese alguma, (pelo menos agora), os Estados Unidos, a Rússia, a China, a França, a Grã-Bretanha e Israel serão interpelados pelos crimes cometidos por seus soldados em diferentes cantos do mundo. Quem ousaria investigar os crimes dos soldados russos na segunda Guerra da Chechênia (1999)? Difícil acreditar na mesma eficácia do TPI diante dos países supracitados em casos de crimes de sua competência com relação aos dirigentes africanos. É questão de competência ou de relação de forças? É uma justiça a duas velocidades ou uma questão de represálias contra os Estados falidos tanto economicamente como politicamente pela ausência de democracia que daria mais credibilidade no processo de governança e de alternância no poder nos moldes dogmáticos ocidentais. 
Para Chantal Del Sol, a justiça internacional condena antes de julgar porque, diante da perversão das políticas, é a moral que se impõe e quer se atribuir o governo dos homens. "A moral visa a se substituir ao Estado, a se atribuir sua autoridade e sua legitimidade para julgar e punir. A justiça internacional apaga o limite entre o direito e a moral. Ela instaura uma nova ordem moral mundial ${ }^{270 "}$ (2004, p.59, tradução nossa).

Percebe-se, desse modo, a necessidade de analisar o impacto da globalização do mundo jurídico, sem apologia à criminalidade, mas prezando pela efetivação de uma justiça que se quer internacional, ou seja, universal, com respeito aos princípios de imparcialidade, de ampla defesa, de contraditório e do devido processo legal sem conotação política para poupar as grandes potências.

\section{Tribunal Penal Internacional e justiça transicional}

Pode-se observar que, nos Estados em Desenvolvimento onde foi adotada a Justiça Transicional para dirimir alguns conflitos e foram instaladas comissões Verdade e Reconciliação, a influência das culturas tradicionais e do poder indígena ou tradicional é onipresente nas relações entre governo central e províncias, e províncias entre elas. As instituições nacionais não podem ignorar o papel do poder tradicional que, na questão agrária, detém a legitimidade e a posse, ou seja, para implantar um projeto de interesse nacional em um determinado local, o Estado deve, antes de execução do mesmo, negociar com o chefe indígena (cacique) a quem cabe o direito de autorizar a execução do projeto de interesse coletivo com reconhecimento ao direito da terra como patrimônio dos autóctones.

Registra-se aqui, a manifestação dos indígenas bolivianos contra o projeto do governo do Evo Morales para a construção de uma estrada financiada pelo Brasil ${ }^{271}$.

Tal fato manifesta, nas culturas indígenas, o vínculo indelével entre os vivos e os mortos, bem como a força do poder tradicional, indispensável nas

\footnotetext{
270 "Devant la perversion des politiques, $c$ ' est la morale qui prend le dessus et veut s'attribuer le gouvernement des hommes. La morale vise à prendre la place de l'État, à s'attribuer son autorité et sa legitimité à juger et à punir. La justice internationale efface la limite entre Le droit et la morale. Elle instaure um ordre moral mondial" (SOL, 2004, p. 59).

${ }^{271}$ Os indígenas bolivianos iniciaram a caminhada em 27 de abril de 2012, na cidade de Trindad, protestando contra a construção de uma estrada financiada pelo Brasil e que cortaria o Território Indígena e o Parque Nacional Isiboro Sécuro (TIPNIS). Disponível em: http://www.gazetadopovo. com.br/mundo/conteudo.phtml?id=1269092\&tit=Marcha-indigena-contra-estrada-financiadapelo-Brasil-chega-a-La-Paz. Acessado em: 27.08.2012. Mais informações disponíveis em: http://www.gazetadopovo.com.br/mundo/conteudo.phtml?tl=1\&id=1265136\&tit=Indigenasmarcham-para-La-Paz-contra-estrada-em-reserva. Acessado em: 27.08.2012.
} 
decisões estatais. $\mathrm{O}$ que reforça a possibilidade de fazer participar o mesmo poder tradicional das resoluções de conflitos mediante a Justiça Transicional para uma paz duradoura na busca da verdade e na releitura da história da sociedade como um todo e na proteção e preservação do Meio Ambiente para um desenvolvimento sustentável, sobretudo por se tratar dos povos indígenas.

Por isso, tal justiça deve ter um efeito conciliador e agregador, ou seja, uma justiça disseminadora de ideia de uma consciência reconciliadora, universal, comunitária e local, e um efeito catalisador quanto à relutância de algumas pessoas a reconhecer os efeitos positivos de reescrever a história sobre a veracidade dos fatos ou dos crimes. É doloroso, mas a comunidade deve se reconciliar consigo mesma para enfrentar o futuro com outros olhares convergentes para um horizonte comum que é o mundo da paz, da fraternidade e da convivência social. Pode ser uma utopia, mas um leitmotiv que alimenta a esperança de lançar as bases de uma paz duradoura, pilar indispensável na construção de um Estado democrático e de direito. Não se pode calar a verdade para que os crimes cometidos nunca mais aconteçam. A paz sustentável é pedra angular de uma sociedade reconciliada com o seu passado e que visa a preservar as gerações vindouras de quaisquer outras atrocidades.

A justiça transicional é um despertar da consciência coletiva e da justiça comunitária baseada no resgate da memória das vítimas sem ódio e sem espírito de revanchismo. Não se trata de uma versão moderna de vingança, mas de uma busca de harmonia e de (re) criação das relações amistosas, harmoniosas e fraternas entre membros de uma mesma comunidade ou de comunidades diferentes, de um mesmo Estado, entre povos diferentes, antes inimigos, ou separados pela dor e mágoa das atrocidades cometidas por algumas pessoas. É uma questão da consciência coletiva que procura recontar, reescrever sua história para as gerações vindouras e melhorar o clima de confiança entre partícipes da mesma comunidade. Trata-se de uma busca de respostas à tamanha barbárie sem precedente e, às vezes, sem explicação e sem motivos relevantes, apenas por questão ideológica ou por puro fanatismo, supriram-se vidas humanas de maneira indiscriminada.

Com efeito, o processo é lento, doloroso porque reabre as feridas do passado, mas necessário por sua eficácia em revelar e fazer conhecer a verdade, nada mais do que a verdade sobre a profanação sistemática do ser humano, a violência sobre aquilo que lhe é sagrado: a dignidade humana.

Nesse sentido, se pode vislumbrar o discurso da Presidenta Dilma Roussef (2012) perante a Comissão Verdade em que ela sublinha a necessidade de conhecer a verdade, pensando nas gerações futuras. Com efeito, “[...] Embora saibamos que regimes de exceção sobrevivem pela interdição da verdade, temos o direito de esperar que, sob a democracia, a verdade, a memória e a 
história venham à superfície e se tornem conhecidas, sobretudo, para as novas e as futuras gerações $[\ldots]^{272}$ ".

Trata-se de um momento histórico para o Brasil, um marco civilizatório para reescrever sua história à luz das mais antigas comissões da verdade já instaladas na Argentina e no Chile sem olvidar a Colômbia. Para a Presidenta, "o direito à verdade é tão sagrado quanto o direito que muitas famílias têm de prantear e sepultar seus entes queridos, vitimados pela violência praticada pela ação do Estado ou por sua omissão ${ }^{273}$ ". Mais adiante, destacando a importância de investigar os crimes cometidos na época da ditadura militar no Brasil (19641985), observa a Presidenta Dilma:

[...] Ao instalar a Comissão da Verdade não nos move, o revanchismo, o ódio ou o desejo de reescrever a história de uma forma diferente do que aconteceu, mas nos move a necessidade imperiosa de conhecê-la em sua plenitude, sem ocultamentos, sem camuflagens, sem vetos e sem proibições. O que fazemos aqui, neste momento, é a celebração da transparência da verdade de uma não que vem trilhando seu caminho na democracia, mas que ainda tem encontro marcado consigo mesma. Nesse sentido... E nesse sentido fundamental, essa é uma iniciativa do Estado brasileiro e não apenas uma ação do governo [...].

Sem sombra de dúvida, descortina-se nesse discurso histórico, um ato do Estado preocupado com a busca da verdade, sem ressentimentos, sem ódio e sem perdão.

Ora, na Justiça Transicional, o oferecimento do perdão é fundamental para que se chegue à uma verdadeira paz entre os acusados e as vítimas ou sua famílias. Deve-se construir a paz pela revelação histórica da verdade que, consequentemente, levará as partes envolvidas à reconciliação com o passado revelado e com a sociedade que sofreu fissuras pelas violações dos direitos humanos mediante torturas ou atos desumanos similares.

Assim, pode-se salientar que a justiça transicional é um resgate de uma consciência coletiva dos princípios da solidariedade e da fraternidade, do amor ágape baseado na aceitação do outro, mesmo sendo criminoso que procura se reconciliar com a comunidade e vítimas ou com as famílias dessas, e na superação das dores e dos sofrimentos. É fase de transcendência das barreiras

\footnotetext{
${ }^{272}$ Discurso da Presidenta da República Federativa do Brasil, Dilma Roussef na Cerimônia de instalação da Comissão da Verdade no Palácio do Planalto em 16 de maio de 2012. Disponível em: http://noticias.bol.uol.com.br/brasil/2012/05/16/leia-a-integra-do-discurso-de-dilma-nacomissao-da-verdade.jhtm. Acessado em: 31.08. 2012).

${ }^{273}$ Idem.
} 
fronteiriças e um repúdio aos estereótipos dogmatizadores, os quais se tornaram paradigmas dominantes intransponíveis perpetuados de geração em geração.

Para retomar a expressão de marketing, a justiça transicional, para sua função conciliadora, é um salto de qualidade nas relações interpessoais, interétnicas em um mundo cheio de contradições e ambivalências enquanto processo construtivo da consciência coletiva.

Antônio Augusto Cançado Trindade (2002, p. 721) ressalta o surgimento de uma nova mentalidade em um mundo em transformação quanto à defesa dos direitos humanos. Com efeito, observa Trindade:

A nova mentalidade que daí surgirá, haverá de manifestar-se, com maior vigor, no seio de uma sociedade mais integrada e imbuída de um forte sentimento de solidariedade humana, sem a qual pouco logra avançar o Direito. Este o memorial em prol de uma nova mentalidade quanto à proteção dos direitos humanos nos planos internacional e nacional, que me permito apresentar a esta III Conferência Nacional de Direitos Humanos, como contribuição, de um brasileiro preocupado com o futuro de seu país, ao debate nacional sobre a matéria. (TRINDADE, 2002, p. 721).

Para o ilustre jurista, uma nova mentalidade emergirá, sobretudo nas novas gerações, a partir da compreensão das novas realidades. Tal compreensão levará à "aceitação da jurisdição obrigatória de um tribunal internacional como a Corte Interamericana de Direitos Humanos" como "algo bom para o país, e sobretudo para seus habitantes, que passam a contar, a par das instâncias nacionais, com o concurso de uma instância internacional para a proteção de seus direitos [...]" (TRINDADE, 2002, p. 720).

Em nome da proteção dos direitos humanos diante das atrocidades indizíveis, e a impunidade de alguns violadores dos direitos supramencionados, torna-se imperiosa a promoção da justiça transicional para "humanizar" as relações entre os povos e para combater as violações sistemáticas dos direitos em tela.

O grande desafio da justiça transicional se refere não apenas ao resgate e à perpetuação da memória, mas também na construção de uma paz duradoura mediante uma 'humanização' profunda das relações interpessoais, ou seja, a fomentação de uma paz que atinja os corações para que não haja sentimentos de ódio nem de vingança e que sejam extirpados na raiz os preconceitos, todas as formas de discriminação.

Daí a necessidade de uma profunda reflexão diante das atrocidades e crimes cometidos em alguns Estados em desenvolvimento, tendo em vista a impunidade de que gozam seus principais atores, refletir sobre o resgate da 
justiça costumeira por uma justiça transicional humanizada ou levantar o desafio de uma humanização da justiça transicional para que além de resgatar a memória das vítimas, promova-se também o processo de reconciliação e perdão, tendo em vista o ser humano como protagonista da construção interior de um novo ser, membro de uma comunidade, construtor de uma paz comunitária e social duradoura, evitando-se atitudes ofensivas e desumanas que acirram os ânimos e criam atritos entre povos que, em princípio, deveriam conviver em paz.

É por isso que a justiça transicional, na busca da verdade e reconciliação entre cidadãos de um mesmo Estado, fica vinculada à própria unicidade estatal baseada no respeito aos direitos humanos, às diversidades culturais de suas populações. A unidade patrial exige uma coexistência pacífica dos diversos povos que compõem o rico mosaico populacional de qualquer Estado. É uma premente necessidade nacional de zelar pela unidade dos povos e pelo respeito dos princípios e valores da vida calcados nas noções de paz e justiça a fim de deixar às gerações novas e futuras um Estado mais justo, fraterno e solidário.

Será que a justiça transicional é uma vocação ou uma vontade nacional? Qual seria a vocação de um Estado, de um governo? E o que é vontade estatal?

A realização de um Estado pacificado deixa a entender que a justiça transicional se encontra nas encruzilhadas dos caminhos que levam à Justiça punitiva nos moldes modernos de julgar e condenar os acusados de crimes de guerra e crimes contra a humanidade e à paz social fundada na busca da Verdade e da ( $\mathrm{Re})$ conciliação através das comissões instaladas ou a serem instaladas em caso de crimes e violações dos direitos humanos.

Por outro lado, é de capital importância ressaltar que há limites interpretativos e restrições hermenêuticas entre justiça transicional e justiça distributiva, punitiva, da competência do TPI, uma vez que na transicional a violação de direitos de terceiros pode ser suprida pela promoção do diálogo e atitudes reparadoras perante a vítima e a comunidade ofendida, enquanto a distributiva preza pela condenação e penalidade como forma de reparação, mas sobretudo de combater a impunidade e a reincidência no que concerne aos crimes considerados gravíssimos com alcance internacional.

Sem embargo, é relevante o processo de criar situações de fronteiras entre ambas as justiças para, com precisão tanto com uma ou com outra, chegar-se à prestação jurisdicional fundada na equidade e na reconciliação assentada no perdão, sem olvidar os princípios gerais de direito que, também, permeiam as culturas na observância de princípios em seu aspecto valorativo e ético.

Sendo o direito dinâmico, deve-se evitar a intransigência para que prevaleça a busca da paz social, como exigência de uma verdadeira justiça em um Estado democrático e de direito. É isto que justifica a própria responsabilidade de Estado em sua dimensão vertical nas relações com os indivíduos, visando, 
para tanto, ao desenvolvimento de relações harmoniosas ou amistosas entre as pessoas, de conformidade com a inteligência da Carta da ONU, requerendo, para isso, uma grande flexibilidade da parte do legislador e das partes envolvidas em conflitos, para que seja almejado o objetivo mais nobre das justiças transicional e distributiva (punitiva): a reparação mediante uma sincera reconciliação, tendo em vista a pacificação dos protagonistas e de suas respectivas comunidades de vida, uma vez que na visão africana, uma comunidade tradicional é como uma teia de aranha: mexer com um dos fios é mexer com todos, ou seja, o individuo enquanto membro da comunidade é carregado por todos. Existe, nesse caso, uma grande cumplicidade entre partícipes, inexistindo a dominação e a exploração. Cada membro se identifica com a totalidade.

Não acreditando na existência de uma comunidade internacional ou comunidade de Estados, mas sim na efetividade de uma sociedade, Valério Oliveira Mazzuoli (2008) enumera os requisitos que compõem uma comunidade. Segundo ele,

[...] a formação de uma comunidade (Gemeinschaft) pressupõe um laço espontâneo e subjetivo de identidade (familiar, social, cultural etc.) entre seus partícipes, em que não exista dominação de uns em detrimento de outros, em tudo diferindo da existência de uma sociedade (Gesellschaft). A sociedade internacional reveste-se de características diametralmente opostas às de uma comunidade. [...] enquanto a comunidade transmite a ideia de convergência e de coesão moral (com nítidos valores éticos comuns), a sociedade demonstra a ideia de divergência, fazendo primar neste ultimo caso - a normalização (legislação, tratados etc.) reguladora de conflitos. (MAZZUOLI, 2008, p.39).

Não obstante os crimes que afetam a comunidade internacional, o advento da justiça transicional não inaugura uma era de impunidade, menos ainda de distribuir cartão verde aos criminosos para persistir no mundo de crimes hediondos como se fosse bônus de violações de direitos humanos, mas se trata de busca de meios justos para proporcionar um equilíbrio essencial à convivência entre povos em conflitos. Nas situações concretas de conflitos que perduram, que se tem a aplicabilidade da justiça transicional entre povos chamados a coabitarem pela determinação geográfica e por questão de identidade cultural.

Sem desconsiderar a importância do TPI para coibir a impunidade dos autores de crimes de maior gravidade e que "constituem uma ameaça à paz, à segurança e ao bem-estar da humanidade ${ }^{274 ",}$, cabe frisar a necessidade da implementação do tribunal no lugar de origem dos acusados, que terão a

${ }^{274}$ Cf. Preâmbulo do Estatuto de Roma da Tribunal Penal Internacional (1998). 
oportunidade de pedir publicamente perdão às vítimas ou famílias de vítimas, bem como às comunidades ofendidas, assim como ocorre com o processo dos Khmers vermelhos em Camboja ${ }^{275}$.

Embora os crimes sejam da competência do TPI, nada impede que o standard dogmático da justiça punitiva funcione de uma maneira híbrida, se enriquecendo de elementos culturais dos Estados ou cidades de origem dos acusados para promover a paz social e comunitária, pois a obstinação de julgálos em território europeu apenas nos moldes de normas ocidentais padronizadas desde Nuremberg pelos crimes cometidos, não alteraria os cenários das atrocidades e a continuidade das mesmas por outros membros, uma vez que as razões são mais profundas do que se imagina, oriundas de velhas veleidades entre povos que se odeiam e cuja insuportabilidade foi acentuada pelos colonizadores para melhor reinar ao favorecer, em certos casos, um dos povos, como ocorreu com os tutsis na administração belga em detrimento dos hutus, povo majoritário em Ruanda e em Burundi ${ }^{276}$.

Vê-se com maior razão que a questão da justiça internacional não pode ser restringida apenas ao modelo paradigmático ocidental da justiça punitiva herdado do modelo dos tribunais militares após a segunda Guerra Mundial. Não há como, na era da globalização, fazer prosperar uma justiça a sentido único, obcecada a julgar criminosos dos Estados pobres e de mero peso no cenário internacional. É difícil ser universal por ser excessivamente seletiva segundo as vozes contrárias à sua efetividade e imparcialidade nos processos ainda em trâmite em Haia.

O desafio é de não analisar a justiça internacional de forma isolada apesar de sua estrutura, pois os casos vigentes no TPI devem ser abordados conforme o contexto em que os fatos aconteceram, ou seja, a sua contextualização deve ser determinante para alcançar o objetivo almejado que é a paz e a segurança internacionais, combatendo-se a impunidade.

Dessa forma, pode-se constatar que a justiça internacional e a justiça transicional não estão em antípoda da paz social em um Estado de direito. São, pelo contrário, duas faces de uma mesma moeda que é a justiça, mas que envolvem diferentes paradigmas oriundos de diversidades culturais e interpretações cosmogônicas. É uma questão da própria sustentabilidade e credibilidade da justiça internacional.

Não se trata de antagonismo entre a jurisdição penal internacional do TPI e a possibilidade de incorporar elementos culturais de solução pacífica de

\footnotetext{
${ }^{275}$ Duc, um dos Khmers vermelhos em uma audiência publica pediu perdão às vítimas e ao povo cambojano.

${ }^{276}$ Vide BRAECKMAN, Colette. Les nouveaux prédateurs : politique des puissances en Afrique Centrale. Fayard : Paris, 2003.
} 
controvérsias numa visão dialogal entre as partes em conflito, menos ainda de contraste, pois o direito da justiça transicional encontra amparo no direito internacional, sobretudo, no direito internacional de direitos humanos. Buscase, portanto, na aplicabilidade e efetividade da justiça transicional coibir as violações sistemáticas de direitos humanos. Não há paradoxo entre a justiça transicional e a justiça internacional em seu aspecto penal, pois ambas tratam da justiça em busca da verdade.

O que se propõe, de fato, é que a produção jurídica de Haia em sua vertente processualística seja enriquecida com outros conhecimentos, pois o conhecimento jurídico nunca será absoluto. A função jurídica deve ser calculada no uso de elementos culturais suscetíveis de favorecer a contribuição para a construção de um direito globalizante e, ao mesmo tempo, específico para julgar em toda imparcialidade casos concretos resultantes de crimes gravíssimos cometidos em determinados lugares com alcance internacional. $\mathrm{O}$ aparelho coercitivo de Haia precisa levar em conta os princípios de eficiência e celeridade processuais.

Longe de legitimar a violência, menos ainda de fazer a apologia de genocídio, de crimes contra a humanidade e crimes de guerra, procura-se trazer à baila um novo olhar sobre o julgamento no âmbito internacional a fim de se evitar um modelo monojurídico e político da jurisdição antes de aplicar todo o aparelho judiciário coercitivo detentor de penalidade.

Com certeza, o fato de manter presos os acusados em Haia, aguardando o julgamento ou a eventualidade da liberdade condicional sob o pretexto de evitar uma hipotética fuga ou intimidação de vítimas ou testemunhas, não condiz com os requisitos de medidas preventivas ou assecuratórias, uma vez que o tempo de detenção vai além do permitido nas legislações internas por questão de inquérito. A detenção prolongada é uma manifestação patética de violação de direitos fundamentais por uma justiça considerada modelo de independência e de imparcialidade e seriedade.

A aplicabilidade de tais mecanismos não rivalizaria com a sofisticada e moderna jurisdição do TPI, mas garantiria a "despolitização" dos processos em Haia conduzidos nos moldes jurisdicionais ocidentais bastante dogmáticos cujas legitimidade e credibilidade são cada vez mais questionadas pelos dirigentes dos Estados em desenvolvimento.

\section{Comissões Verdade E (RE)CONCILIAÇÃo OU JUSTIÇA PóS-CONFLitos}

Compreender o funcionamento das Comissões Verdade e (Re) Conciliação (CVR), seu mecanismo de abordagem dos crimes cometidos e promover a paz, a harmonia entre os povos, a unidade nacional, a valorização da (re) conciliação 
sem favorecer a impunidade nem a anarquia em Estado democrático e de direito, constitui o grande objetivo e, ao mesmo tempo, o desafio a ser superado pelas Comissões CVR.

Não se pode imaginar a instalação da CVR sem a existência de um Estado de direito que combata a corrupção, o tráfico de influência, os crimes de colarinhos brancos e a impunidade. Nos dizeres do professor Ngoma Binda (2008), a CVR contribui para a construção da paz. "A necessidade de criar o Estado de direito impõe uma luta implacável e impiedosa contra a anarquia e a impunidade acima, apesar da exigência de reconciliação que clama o fulgor do nosso desejo de paz de unidade e de harmonia expressado na filosofia de toda Comissão da Verdade e da Reconciliação ${ }^{277 " ' ~(t r a d u c ̧ a ̃ o ~ n o s s a) . ~}$

O objetivo primordial de uma CVR é acima de tudo a luta contra a impunidade, tendo em vista o restabelecimento de um Estado de direito onde a justiça e a paz se abraçam ${ }^{278}$.

Daí a indagação se a concessão de anistia é uma maneira de promover a paz social e o perdão coletivo ou um bônus acordado aos criminosos para apagar os crimes gravíssimos cometidos a fim de escapar à Justiça internacional? Será que tal atitude benevolente favorece a impunidade ou torna-se salutar para o restabelecimento da paz social em nome da unidade nacional a ser consolidada urgentemente?

No mesmo sentido, pergunta-se, como conceder a anistia sem ofender e nem vilipendiar a memória das vítimas? Podem-se estabelecer categorias de crimes a serem perdoados e outros a serem esquecidos, evitando-se dar a impressão de favorecer ou oficializar a impunidade?

O grande desafio é criar um paralelo entre o TPI e a CVR em termo de colaboração, vislubrando-se o papel do TPI em punir os crimes graves de maior alcance internacional e o da CVR, o qual consiste a estabelecer os fatos, lutando contra a impunidade, mas, ao mesmo tempo, promovendo o perdão internamente aos criminosos.

Nessa ótica, pode-se entender a lógica de uma Comissão da verdade quanto à reconciliação que, também implica a exigência de conceder a anistia aos acusados, podendo ser perdoados ou esquecidos, em nome de mais elevado interesse da nação. Indaga-se, portanto, Ngoma-Binda, se tal atitude seria o caminho do compromisso e comunhão? Com efeito,

\footnotetext{
277 "la necessité de créer l"Etat de droit impose une lutte acharnée e impitoyable contre l"anarchie e l'impunité au-delà et en dépit de l'exigence de réconciliation qu"appelle la fulgurance de notre désir de paix, d"unité et d"harmonie exprime dans la philosophie de toute Commission de Vérité et de Réconciliation.

${ }^{278}$ Vide Salmo 84/85: "Amor e Verdade se encontram, Justiça e Paz se abraçam; da terra germinará a Verdade, e a Justiça se inclinará do céu." (Sl 85 (84): 11).
} 
O senso moral indica que é profundamente injusto, muito perigoso e inaceitável de consagrar a impunidade. No entanto, se nós queremos absolutamente chegar a construir uma sociedade democrática, somos forçados a escolher o caminho do compromisso e da comunhão de corações. Ele nos faz olhar para o futuro ao invés de nos atolar e nos fazer caminhar no passado. Somos obrigados a superar nossas tristezas e dores, morais e físicas, quaisquer que sejam sua extensão e sua profundidade em nossas almas e nossas famílias. É doloroso perdoar, reconciliar-se com os próprios algozes, mas é o caminho da paz, do progresso e da vida harmonizada, feliz (NGOMA-BINDA, 2008, p. $107)^{279}$ (tradução nossa).

\subsection{ENTENDIMENTO DA JUSTIÇA TRANSICIONAL NO ÂMBITO INTERNACIONAL}

No tocante ao TPI e à justiça transicional, deve-se lembrar, em primeiro lugar, que a batalha entre Justiça, impunidade e reconciliação é árdua e complexa, pois há vários fatores que intervém na sociedade.

A outra grande batalha seria a reconstrução do Estado de direito, focando mais na reconstrução econômica, judiciária e sanitária, bem como na investigação dos crimes de maior gravidade, enquanto exigência ou obrigação em direito internacional. Procurar" pôr fim à impunidade dos autores desses crimes e a contribuir assim para a prevenção de tais crimes" 280 é um dos aspectos da reconciliação.

Pode-se ressaltar que, no que concerne ao binômio reconciliação-verdade, não há reconciliação sem falar da verdade, pois se espera um diálogo franco entre vítimas e algozes, no sentido de levar as vítimas ao reconhecimento de seus algozes, e estes ao reconhecimento de seus crimes ${ }^{281}$.

Urge frisar que a verdadeira reconciliação passa pela verdade da história. É justamente o que se espera da Justiça Transicional, em consonância com a justiça distributiva que, em seu turno, se apega tanto às normas locais como às normas internacionais.

\footnotetext{
279 "Le sens moral indique que c'est profondément injuste, très dangereux et inacceptable de consacrer l'impunité. Néanmoins, si nous voulons absolument arriver à construire une société démocratique, nous sommes acculés à emprunter la voie Du compromis et de la communion des coeurs. Elle nous fait regarder vers Le futur plutôt que nous enliser et nous faire patauger dans Le passe. Nous sommes obligés de surmonter nos peines et douleurs, Morales et physiques, quelles que soient leur étendue et leur profondeur dans nos âmes et nos familles. C"est douloureux de pardonner, de se réconcilier avec ses propres bourreaux, mais c"est Le chemin de la paix, du progrès et de la vie harmonisée, heureuse" (NGOMA-BINDA, 2008, p. 107).

${ }^{280}$ Cf. Preâmbulo de Estatuto de Roma de Tribunal Penal Internacional de 1998.

${ }^{281}$ Trata-se do processo que ocorreu em Burundi, na África do Sul através das Comissões Verdade e Reconciliação.
} 


\subsection{Natureza jurídica da Comissão Verdade e ReconciliaÇão (CVR)}

A CVR não é um tribunal para julgar e condenar, mas pode corroborar para que a justiça seja feita dentro da lógica da complementaridade com os mecanismos judiciários já existentes. Não há sentença, mas nada impede que ela solicite reparações pelas vítimas de violações dos direitos humanos, mesmo não tendo competência sobre os crimes do TPI, crimes imprescritíveis. Ela tem por missão levar tanto os autores de crimes como as vítimas a dizer a verdade, e às vítimas propor a oportunidade de se reconciliar com os autores e perdoálos. A paz duradoura passa pela reconciliação e pelo perdão, bem como o desenvolvimento sustentável.

Procura-se valorizar o sentido da reconciliação e do resgate da memória das vítimas, da reconquista da história em prol de uma paz duradoura. A verdade liberta. Pode-se indagar, afinal, o que é a verdade? Dizer a verdade não é busca de vingança ou revanchismo, menos ainda de fazer sofrer os autores, uma vez conhecidos os motivos dos crimes cometidos. A verdade deve ser o caminho para a paz. Uma busca contínua de reconciliação com o passado, mas também com a própria pessoa, vítima de crimes perpetuados, sem ódio e sem revanchismo.

\subsection{NOVA FORMA DE COMUNICAÇÃO E INSTAURAÇÃO DE UM DIÁLOGO SUSTENTÁVEL}

Questionado pela jornalista Laure Constantineo sobre como uma população pode superar um crime contra a humanidade da qual havia sido vítima, Yves Ternon ${ }^{282}$, médico e historiador que se consagrou à pesquisa sobre os crimes contra a humanidade e, particularmente, sobre os genocídios judaico, armênio e ruandês, sobre os quais escreveu numerosas obras, assevera que, antes, deve-se saber em que medida a população está consciente da natureza da criminalização, dos crimes dos quais ela havia sido vítima: crimes de guerra, crimes contra a humanidade, genocídio. Como superá-los? A população, segundo Yves Ternon, não saberá superá-los enquanto guardar sequelas ou marcas dos mesmos, durante várias gerações, devendo-se remontar aos crimes das guerras do século XX. Não há apagamento de marcas que, ao contrário, permanecem; mas o estabelecimento da verdade, o reconhecimento dos fatos para os sobreviventes e para os descendentes das vítimas é um momento essencial para a memória. O processo só pode ocorrer com os indivíduos vivos.

$\mathrm{Na}$ mesma esteira, ressalta Yves Ternon que a grande especificidade do direito internacional no século XX é que o processo instaurou-se contra os

\footnotetext{
${ }^{282}$ Trata-se de uma entrevista concedida à jornalista Laure Constantineo. Disponível em: http:// www.tv5.org/TV5Site/publication/galerie-204-5-Le_Crime_contre_lhumanite.htm/.
} 
indivíduos e não mais contra as entidades virtuais, os Estados, as nações. A partir do fim da primeira guerra mundial, foram estabelecidos princípios para a punição, para a repressão de crimes contra os indivíduos que agiram ou foram responsáveis em nome de um Estado ou no quadro de um Estado. A efetividade se deu a partir da segunda guerra mundial.

Indagado sobre a necessidade do processo sobre o Camboja, Yves Ternon, além de manifestar-se a favor, lamenta, ainda, seu efeito tardio e manifesta também a sua preocupação para com os sobreviventes pelo fato de os acusados estarem vivos, pois viver com os criminosos, para os sobreviventes, é terrivelmente angustiante, doloroso, como é o caso do Camboja e de Ruanda, na medida em que a verdade não havia sido estabelecida e a acusação, verdadeiramente, não havia sido feita.

Importante ressaltar também que no tocante aos crimes especificados nos artigos $5^{\circ}$ e $6^{\circ}$ do Estatuto de Roma, os acusados podem ter exercido papéis diferentes no momento de cometimento dos crimes, mas isso não os exime de suas responsabilidades, menos ainda de serem acusados por prática de crimes de guerras, crimes contra a humanidade e genocídio.

Para Yves Ternon, "o estabelecimento da verdade é um momento essencial para as vítimas ${ }^{283 "}$ ". Cumpre-se, nesse caso, destacar os sentimentos que envolvem as vítimas, divididas entre o alívio e a ansiedade. Entende-se por alívio, o fato de poder dar a palavra às vítimas, considerando a atuação dos juízes em toda a liberdade e independência e espírito do perdão e da busca da verdade.

O reconhecimento dos erros cometidos e assumidos publicamente acarretará, eventualmente, o perdão ou a sua rejeição da parte das vítimas ou de suas famílias. Nota-se que, na busca pela existência de relação em duplo sentido, encontra-se, de um lado, o culpado que tem direito ao perdão da parte das vítimas e, do outro, as vítimas a quem é oferecido perdão pelo culpado em nome da paz, porém cabe às vítimas o direito de perdoar, pois o perdão é pessoal e depende de cada vítima.

Não se pode olvidar que a ONU é fundadora dos tribunais penais internacionais ad hoc, mediante a atuação do Conselho de Segurança e que mantém relação com a Corte Penal Internacional, conforme estipulado no art. $2^{\circ}$ do Estatuto de Roma.

Art $2^{\circ}$ do Estatuto de Roma: "A relação entre o Tribunal e as Nações Unidas será estabelecida através de um acordo a ser aprovado pela Assembleia dos Estados Partes no presente Estatuto e, em seguida, concluído pelo Presidente do Tribunal em nome deste".

${ }^{283}$ Op.cit. 
Sabe-se, contudo, que a ONU teve um papel fundamental na criação dos Tribunais Penais Internacionais sobre a ex Iugoslávia ${ }^{4}$ e sobre Ruanda ${ }^{284}$. É imperioso registrar que a ONU exerce um papel importantíssimo sobre a legitimidade e a criação dos tribunais penais internacionais, apesar das dificuldades que, muitas vezes, enfrenta para a instalação dos mesmos tanto pela falta de colaboração de alguns Estados, como pelo deslocamento do pessoal e das testemunhas.

Pode-se, nesse caso, incorporar regras de uma legislação interna em um processo internacional para julgar cidadãos daquele Estado acusados de crimes de genocídio, crimes de guerra e crimes contra a humanidade, como é o caso do processo dos Khmers Vermelhos em Camboja. Reconhece-se, contudo, o princípio de complementaridade da Corte Penal Internacional, mas no caso em tela, não se trata disso, uma vez que os acusados não são julgados para somente e exclusivamente segundo a legislação penal cambojana, mas segundo as regras do Direito Penal Internacional.

Vale ainda lembrar que as regras usadas no Direito Penal Internacional são, na realidade, regras inspiradas pelo procedimento anglo-saxão, como por exemplo, a ausência da parte civil.

Assim, não se pode perder de vista, o que se visa obter em tais processos penais internacionais: a questão do ressurgimento da confiança entre os acusados ou algozes e as vítimas dos crimes indizíveis com respeito às normas internacionais, princípios gerais de direito, as convenções internacionais e aos costumes internacionais, tendo em vista um justo julgamento com juízes internacionais dentro dos princípios de independência, imparcialidade.

Tanto a comunidade internacional como as vítimas ou famílias de vítimas, com a instalação de tais processos, se espera, no mínimo, que os acusados de crimes graves de alcance internacional, reconheçam, pelo menos, os atos bárbaros que praticaram e digam o porquê de tantas atrocidades, pois o mais importante não é a reparação material, mas o resgate e a conservação da memória, pois sem justiça, não há memória.

Há, portanto, necessidade de promover a verdade para que os crimes gravíssimos nunca mais se repitam para o bem das gerações futuras. É nesse sentido que aborda a Presidente Dilma Roussef em seu Discurso para a instalação da Comissão da Verdade no Palácio do Planalto:

A ignorância sobre a história não pacifica, pelo contrário, mantêm latentes mágoas e rancores. A desinformação não ajuda apaziguar,

\footnotetext{
${ }^{284}$ Vide notícias sobre o Tribunal Penal Internacional para a Ex-Iugoslávia. Disponível em: http:// translate.google.com.br/translate?hl=pt-BR\&langpair=en\%7Cpt\&u=http://www.icty.org/. Acessado em: 31.08.2012.
} 
apenas facilita o trânsito da intolerância. A sombra e a mentira não são capazes de promover a concórdia. O Brasil merece a verdade. As novas gerações merecem a verdade e, sobretudo, merecem a verdade factual aqueles que perderam amigos e parentes e que continuam sofrendo como se eles morressem de novo e sempre a cada dia. É como se disséssemos que, se existem filhos sem pais, se existem pais sem túmulos, se existem túmulos sem corpos, nunca, nunca mesmo, pode história sem voz. E que dá voz à história são os homens e as mulheres livres que não têm medo de escrevê-la. Atribui-se a Galileu Galilei uma frase que diz respeito a este momento que vivemos: "a verdade é filha do tempo, não da autoridade ${ }^{285}$.

\section{A Comissão Verdade e ReconciliaÇão: desafios}

Toda Comissão de Verdade tem por objetivo primordial lutar contra a impunidade, ou seja, fazer com que o direito seja dito, seja restabelecido o Estado democrático e de direito para a efetividade da justiça. Além de buscar estabelecer a responsabilidade pelos crimes praticados, procura-se, ao mesmo tempo, a verdade para que seja conhecida e que ela brote do culpado para que seja oferecido o perdão em vista da Reconciliaçao. Como diz Ngoma Binda, "a verdade conduz à reconciliação. A reconciliação social e política geram a paz social e constrói o Estado de direito" (BINDA, 2008, p.119). A construção de um Estado deve ser o objetivo cardeal de uma Comissão Verdade e Reconciliação, pois, nos dizeres de Ngoma Binda, "a ausência do Estado é sinônimo de anarquia (p.119)".

Nesse caso, considerando o interesse maior da nação, deve-se evitar quaisquer comportamentos que possam atrapalhar a construção de um Estado pós-conflitos. Por isso, a reconciliação é um dos pilares de que um Estado precisa para se desenvolver, porque uma vez a reconciliação promovida entre seus membros, todos terão um ideal comum, evitando-se interesses egoístas.

Segundo Ngoma Binda (2008, p. 119), “a reconciliação pressupõe, então, lutar com determinação contra a corrupção, um mal particularmente profundo que mina e destrói todos os esforços de desenvolvimento, bem como o estabelecimento de direito e de justiça social".

A missão da Comissão da Verdade instalada no Brasil pela Presidente Dilma é árdua, considerando o período das investigações (1946-1988). Não se pode falar apenas da verdade sem pensar também na consolidação da paz da

\footnotetext{
${ }^{285}$ Discurso da Presidente Dilma Roussef na instauração da Comissão da Verdade no Palácio do Planalto em 16 de maio de 2012. Op.cit.
} 
unidade nacional graça a uma verdadeira reconciliação entre brasileiros. Quanto aos meios para almejar tal missão, precisa-se de restabelecimento da verdade sobre as violações maciças dos direitos humanos e da promoção da paz, da justiça, da reparação, do perdão e da reconciliação. Trata-se, entre outras, de fazer com que tanto as vítimas dos crimes cometidos ou sofridos como os autores ou os acusados se reconciliem para o bem da nação brasileira, de sua unidade no caminho do desenvolvimento sustentável, o qual passa pela promoção da paz duradoura e pela construção de uma sociedade justa, igualitária e fraterna.

Neste caso, nota-se a relevância da Comissão da Verdade num processo democrático. Ela contribui à construção do país, fazendo devolver não apenas a paz, mas também a confiança entre seres humanos condenados a trabalhar juntos para o bem-estar de todos e de conviver com espíritos acalmados, o coração reconciliado com o outro e ter a capacidade e a coragem de estender a mão ao outro sem espírito ódio, sem vingança, mas superando tudo para que prevaleça o amor.

Faz parte de mecanismos para administrar conflitos, preveni-los e saber curar as sequelas que eles deixam no ser humano, muitas vezes, difíceis para curar e lembranças complicadas para apagar por ter vivenciado atrocidades, crimes inimagináveis e indizíveis.

O grande desafio é promover a coabitação entre vítimas ou parentes de vítimas com os acusados ou autores. É necessário recriar as coisas, fazer coisas novas, com uma nova consciência patriótica e, ao mesmo tempo, promover uma educação cívica, patriótica, mostrando um ideal comum a ser alcançado e, na medida do possível, criar um fundo para reparação das vítimas.

\subsection{CoMissão VERdAde E RECONCILIAÇÃo: UMA LUTA CONTRA A IMPUNIDADE}

Pode-se lutar pela eficácia da instalação das comissões Verdade e Reconciliação, uma vez superado o espírito de vingança que rodeia qualquer ser humano em tempo de conflitos quando se perde um ente querido nas violências inexplicáveis. O desafio é como superar o dogmatismo de uma justiça com rosto ocidental na sua modalidade de justiça punitiva ou distributiva?

Há crimes que são do TPI, mas seria interessante criar mecanismos de cooperação para que alguns elementos culturais possam servir para julgar o autor de crimes, mesmo da competência do TPI, a se reconciliar com a coletividade ofendida pelos crimes cometidos. O que adianta confinar um criminoso em Haia enquanto seus adeptos milicianos ou membros da tribo continuam a luta armada cometendo os mesmos crimes?

Não há julgamento na CVR nos moldes da justiça penal tradicional, mas a escuta é necessária como terreno de reconciliação e de perdão. Torna-se 
necessário encaminhar perante as autoridades competentes os crimes cometidos a fim de punir os responsáveis. Na realidade por se tratar de uma punição psicológica, observa-se que o ser humano incriminado, ao revelar o fato, se humilha e busca a cura dos tormentos e fantasmas das vidas ceifadas.

\subsection{Comissão Verdade e Reconciliação para construção de UM ESTADO DE DIREITO}

É um mecanismo que ajudaria muito para promover a coabitação pacifica, não sem dores, mas caminho obrigatório para curar cicatrizes e conviver harmoniosamente sem rancor. O caminho é árduo, mas em cooperação com outras entidades políticas, administrativas e militares a justiça transicional não deixa de ser um dos pilares de garantia e efetividade de direito para a construção de uma paz duradoura e de um Estado democrático e de direito.

Acredita-se na construção de um Estado de direito se houver vontade política para superar as atrocidades que macularam muitas comunidades. A CVR é um apoio a todo o processo democrático, pois ela devolve a confiança além de criar um clima de paz e de prevenção aos conflitos.

Cabe lembrar, contudo, no tocante ao Brasil, longe das polêmicas doutrinárias, já superadas, referentes à entrega ou extradição do nacional perante o TPI, a inteligência do art. $5^{\circ}, \S 4^{\circ}$-, da Constituição Federal de 1988: "O Brasil se submete à jurisdição de Tribunal Penal Internacional a cuja criação tenha manifestado adesão". Neste caso, não se trata de extradição do nacional ao TPI, mas uma transferência do nacional a uma organização internacional, pois a extradição como instituto jurídico existe entre Estados soberanos mediante tratado ou termo de reciprocidade, e, na falta desses instrumentos, ocorre por via diplomática ou de governo a governo. Antes do Estatuto de Roma entrar em vigor em 2002, o Brasil já havia iniciado a reforma judiciária que acarretou mudanças pela Emenda Constitucional 45/2004.

Antes disso, há de se ressaltar que no ordenamento jurídico interno, segundo o art. 84,VIII da Carta Magna, a celebração de tratados, convenções e atos internacionais, sujeitos a referendo do Congresso Nacional, é da competência privativa do Presidente da República. Cabe, nesse caso, ao Congresso resolver definitivamente dos tratados, com fulcro no art. 49, I da mesma Constituição Federal de 1988.

Nessa ótica, o Estatuto foi aprovado em 6 de junho de 2002 por meio do Decreto Legislativo 112 e, em seguida, o Chefe do Executivo fez o depósito do instrumento de ratificação perante o Secretário - Geral das Nações Unidas. Assim como observa Renata Mantovani de Lima (2006), “[...] a finalização da 
etapa interna de inserção do Estatuto de Roma no ordenamento jurídico pátrio foi formalizada pela promulgação, em 25 de setembro de 2002, do Decreto presidencial 4.388" (LIMA, 2006, p. 153).

Com efeito, a EC45/2004, fez incorporar na Constituição Brasileira de 1988 inovações com destaque dos Direitos Humanos, manifestando claramente a adesão e submissão do Brasil ao Estatuto de Roma.

Art. 5-, parágrafo $4^{\circ}$-, da $\mathrm{CF} / 88$ : “O Brasil se submete à jurisdição de Tribunal Penal Internacional a cuja criação tenha manifestado adesão".

Concernente os Direitos Humanos, pode-se salientar a importância do mesmo art. $5^{\circ}$ - da Constituição Federal em seu parágrafo $3^{\circ}$-, tendo em vista a força normativa constitucional dos tratados e convenções internacionais.

\section{Conclusão}

Tendo em vista as críticas contra o Tribunal Penal Internacional por ser uma jurisdição seletiva, assimétrica e discriminatória, sugere-se que o exercício da função jurídica seja feito a base de reconhecimento e adoção de normas internas abarcadas nos bons costumes e na equidade, dentro da razoabilidade e proporcionalidade, para que possam contribuir para a construção de um direito globalizante, ao mesmo tempo, especifico para julgar casos concretos resultantes de crimes gravíssimos cometidos em determinados lugares com alcance internacional. $\mathrm{O}$ aparelho coercitivo da Haia precisa levar em conta o principio de eficiência. Não é questão, contudo, de legitimar a violência ou de fazer apologia aos crimes gravíssimos contra a pessoa humana, nem de premiar os acusados, mas de evitar que um modelo de uma justiça condenatória, punitiva nos moldes ocidentais e monopolítico se torne um modelo jurisdicional universal seguindo os passos de Nuremberg onde os aliados vencedores tiveram vez e voz.

Por oportuno, resta reafirmar a necessidade de uma Justiça Transicional nos Estados em desenvolvimento submetidos a regimes ditatoriais, especialmente, na América Latina, no intuito de criar bases sólidas para a construção de Estados verdadeiramente democráticos e de direito, conscientes de seu passado, mesmo assombrado, e de suas potencialidades para superar as atrocidades, visando à manutenção da paz social como fator primordial no processo da restauração da democracia e da promoção pelo desenvolvimento sustentável. 


\section{REFERÊNCIAS}

BAZELAIRE, Jean-Paul; CRETIN, Thierry. A Justiça Penal Internacional: sua evolução, seu futuro de Nuremberg à Haia. São Paulo: Manole, 2004.

BINDA, Ngoma. Une démocratie libérale communautaire pour la République $d u$ Congo et l'Afrique. Paris: L'Harmattan, 2001.

BOBBIO, Norberto. A Era dos direitos. Trad. Carlos Nelson Coutinho. Rio de Janeiro: Campus, 1992.

BRAECKMAN, Colette. Les nouveaux prédateurs : politique des puissances en Afrique Centrale. Fayard : Paris, 2003.

CHOMSKY, Noam. O império americano: hegemonia ou sobrevivência. Trad. Regina Lyra. Rio de Janeiro: Elsevier, 2004.

DAHLKE, Rüdiger. Qual é a doença do mundo? Trad. Luiz A. de Araújo, São Paulo: Cultrix, 2011.

DELSOL, Chantal. La grande méprise: justice internationale, gouvernement mondial, guerre juste... Paris : La Table Ronde, 2004.

FOUCAULT, Michel. Vigiar e Punir: história da violência nas prisões. 4. ed. Rio de Janeiro: Vozes, 1986.

HÖFFE, Ortfried. A democracia no mundo de hoje. São Paulo: Martins, 2005.

HOUGUEBIE, Fabrice. La notion de "justice transitionnelle" a-t-elle um sens? Disponível em: http://www.droitconstitutionnel.org/congresParis/comC5/ HourquebieTXT.pdf. Acessado em: 31.08.2012.

LEWANDOWSKI, Enrique Ricardo. Globalização, regionalização e soberania. São Paulo : ed. Juarez de Oliveira, 2004.

LIMA, Renata Mantovani de.; BRINA, Mariana Martins da Costa. O Tribunal Penal Internacional. In Leonardo Nemer Caldeira Brant (Coord.) Coleção Para Entender. Belo Horizonte: Del Rey, 2006.

LLOPIS, Ana Peyró. La compétence universelle en matière de crimes contre l'humanité. Bruxelles : Bruylant, 2003. 
LOQUIN, Eric; KESSEDJIAN (Dir.) La mondialisation du droit.v.19, Litec, 2000.

MAZZUOLI, Valério de Oliveira. Curso de direito internacional público. 3. ed. São Paulo: Editora Revista dos Tribunais, 2008.

MAZZUOLI, Valério de Oliveira (Org.) Coletânea de Direito Internacional, Constituição Federal. São Paulo: Ed. Revista dos Tribunais, 2009.

ORTIZ, Renato. Mundialização, cultura e política. In Desafios da globalização. (Org.) Ladislau Dowbor, Octávio Ianni, Paulo-Edgar A. Resende. Petrópolis: Vozes, 1997.

PARENTI, Pablo F. Informes nacionales - Argentina - In: AMBOS, Kai; MALARINO, Ezequiel; WOISCHNIK, Jan (ed.) Dificultades jurídicas y politicas para la ratificación o implementacion del Estatuto de Roma. Montevideo: Fundación Konrad Adenauer, 2006.

PETIT, Jean-Phillipe. Tribunal Pénal International pour l'ex-Yougoslavie. Le Procureur c. Zoran Kupreskic et consorts, IT-95-16-A, Chambre de première instance II, Jugement, 14 jan. 2000. Disponível em: http://www.ridi.org/adi/ dip/tpiy2000kupreskic.htm/. Acessado em: 26.10.2010.

PATRICK Daillier; PELLET, Alain. Droit internacional public. 7 ed. Paris: LGDJ, 2002.

PEYRÓ LLOPIS, Ana. La compétence universelle em matière de crimes contre l'humanité. Bruxelles: Bruylant, 2003.

PIOVESAN, Flávia. Direitos Humanos, globalização economica e integração regional: desafios do Direito Constitucional Internacional. São Paulo: MaxLimonad, 2002.

PIOVESAN, Flávia. Direitos humanos e Justiça Internacional: um estudo comparativo dos sistemas regionais europeu, interamericano e africano. São Paulo: Saraiva, 2006.

PONTO-GONÇALVES, Carlos Walter. A globalização da natureza e a natura da globalização. Rio de Janeiro: Record, 2006. 
RAWLS, John. O direito dos povos. Trad. Luís carlos Borges. São Paulo : Martins Fontes, 2001.

ROSSI, Clóvis, Globalização diminui as distâncias e lança o mundo na era da incerteza. In Folha de São Paulo, São Paulo, 02 nov. 1997, Caderno Especial.

RIBEIRO, Fernando Armando. Conflitos no Estado Constitucional Democrático: por uma Compreensão jurídica da Desobediência Civil. Belo Horizonte : Mandamentos, 2004.

ROULOT, Jean-François. Le crime contre l"humanité. Paris : L"Harmattan, 2002.

RORTY, Richard. Verdade e progresso. Trad. Denise R. Sales. Barueri: Manole, 2005.

SANTOS, Boaventura de Sousa. O discurso e o poder: ensaio sobre a sociologia da retórica jurídica. Porto Alegre: Fabris, 1988.

SILVA, Luiz Gonzaga. Globalização e Estado Contemporâneo. São Paulo: Memória Jurídica Editora, 2001.

STEIN, Ernildo. Sobre a Verdade. Lições Preliminares ao Parágrafo 44 de Ser e Tempo. Ijuí: Ed. Unijuí, 2006.

SUSIN, Luiz Carlos; Aquino, María Pilar. Reconciliação num mundo de conflitos. Revista Concilium. Petrópolis: Vozes, 2003.

TRINDADE, Antonio Augusto Cançado. A humanização do direito internacional. Belo Horizonte: Del Rey, 2006.

TRINDADE, Antônio Augusto Cançado. Direito das Organizações Internacionais. 3. ed. Belo horizonte : Del Rey, 2002.

TRINDADE, Antonio Augusto Cançado. O direito internacional em mundo em transformação. Rio de Janeiro: Renovar, 2003.

TRINDADE, Antônio Augusto Cançado. Tribunais internacionais contemporâneos: coexistência e expansão. Revista Del Rey Jurídica. Ano 8, n. $16.1^{\text {o }}$ semestre 2006. 